\title{
A simple method to determine the proper length of the gastric myotomy during peroral endoscopic myotomy for achalasia
}

Peroral endoscopic myotomy (POEM) was first performed in 2008 by Inoue and since then has been used widely, with noninferiority to Heller's myotomy [1]. A critical step during POEM is ensuring an appropriate length of the gastric myotomy $(2-2.5 \mathrm{~cm})$, as a short myotomy can lead to a lack of response, and if too long, a higher incidence of moderate reflux esophagitis may occur without improving clinical efficacy [2, 3].

Various methods of verifying the proper extent of the tunnel have been described: use of a double scope for transillumination at the gastric cardia [4]; identification of the two penetrating vessels during posterior POEM [5]; distance from incisors (insertion depth); intraprocedural X-ray; or injection of indocyanine green into the submucosa on the gastric

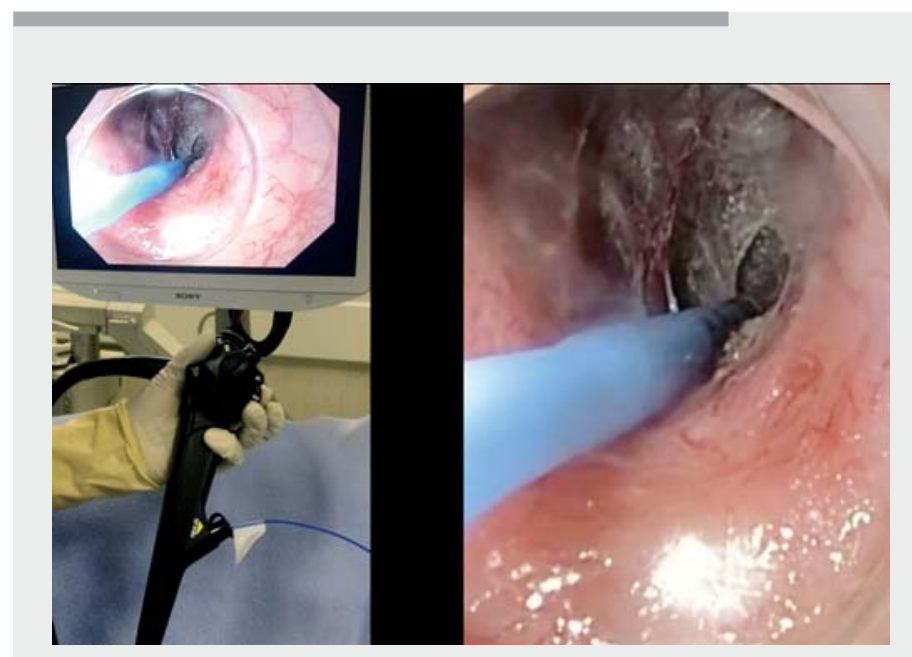

Video 1 A simple method to ensure a 2-cm gastric myotomy during peroral endoscopic myotomy.
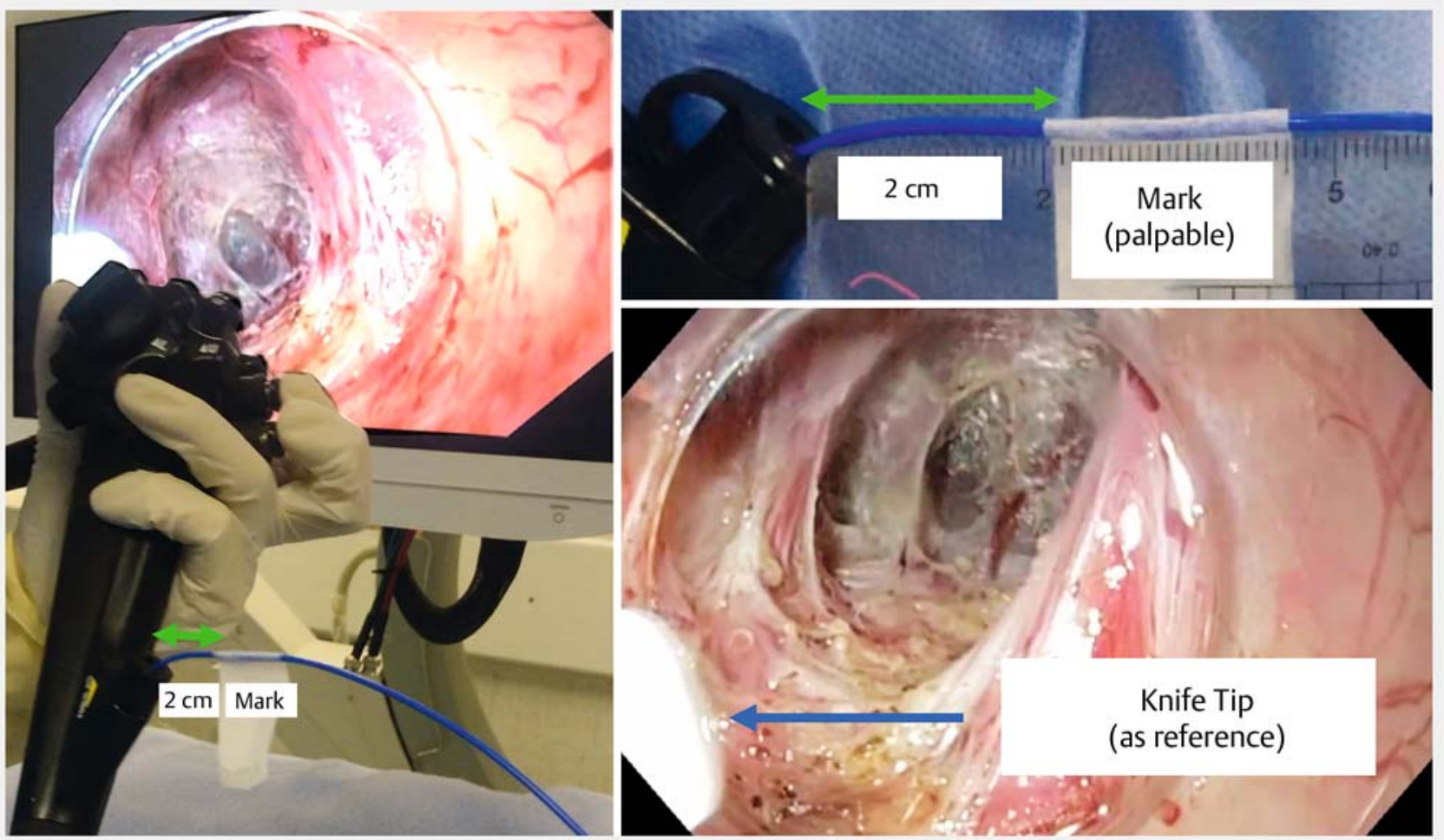

- Fig. 1 The tip of the scope is positioned at the esophagogastric junction, with the knife placed outside the working channel, just far enough to see the tip in the screen. With the help of a ruler, a mark is placed on the knife $2 \mathrm{~cm}$ from the endoscope channel. 

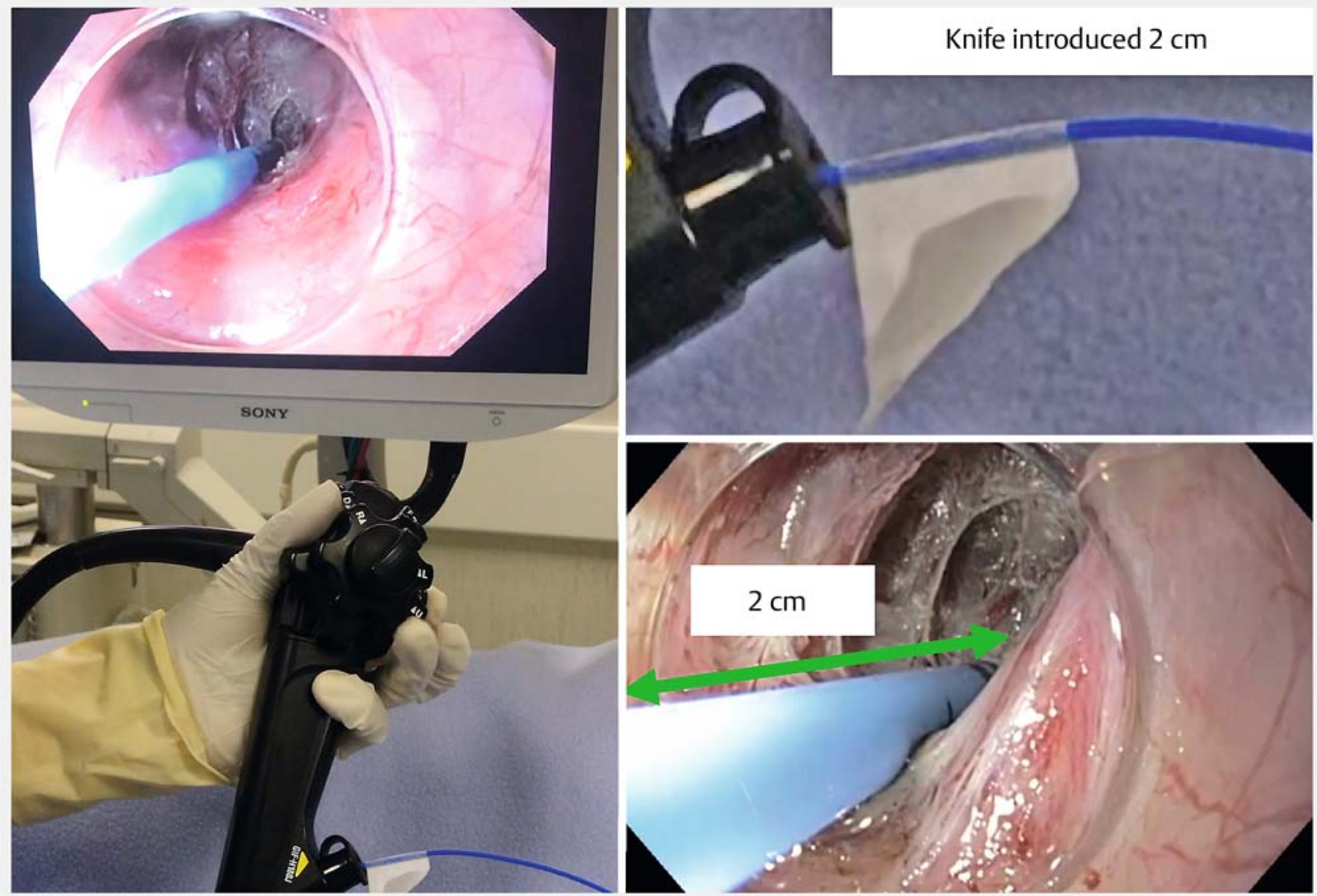

- Fig. 2 Under endoscopic visualization the knife is gently advanced right above the muscularis propria until the 2-cm mark reaches the end of the tunnel or the entrance of the working channel. Using this method, we can see when the submucosal tunnel has reached $2 \mathrm{~cm}$ in length on the gastric side, and therefore the gastric myotomy would be appropriate.

side before tunneling. However, none of these methods measure the distance from the esophagogastric junction (EGJ) to the end of the tunnel. We present a simple method that might help to ensure a 2-cm gastric myotomy ( $>$ Video 1 ).

Once the submucosal tunnel seems to be appropriate, the tip of the scope is positioned at the EGJ, usually recognized as a narrowing area followed by expansion of the submucosal space, and the tip of the knife is placed outside the working channel, just far enough to see the tip in the screen. Externally, with the help of a ruler, a mark is placed on the knife $2 \mathrm{~cm}$ from the endoscope channel ( $\mathbf{F i g} \mathbf{1}$ ). Then, under endoscopic visualization, the knife is gently advanced right above the muscularis propria until the $2-\mathrm{cm}$ mark reaches the entrance of the working channel or the end of the tunnel ( Fig.2). Using this method, we can see when the submucosal tunnel has reached 2-cm in length on the gastric side, and therefore the gastric myotomy would be appropriate.

Endoscopy_UCTN_Code_CCL_1AB_2AC_3AD

Competing interests

The authors declare that they have no conflict of interest.

\section{The authors}

Hugo Uchima ${ }^{1}$, Juan Colán-Hernández¹,

Ariadna Aguilar ${ }^{2}$, Jenny Haya ${ }^{3}$, Eugeni

Domènech $^{4,5}$, Vicente Moreno ${ }^{1}$, Ingrid Marín ${ }^{2}$

1 Endoscopy Unit, Gastroenterology Department, Hospital Universitari Germans Trias i Pujol, Badalona, Barcelona, Spain

2 Motility Disorders Unit, Gastroenterology Department, Hospital Universitari Germans Trias i Pujol, Badalona, Barcelona, Spain
3 Gastroenterology Department, Althaia, Manresa, Barcelona, Spain

4 Gastroenterology Department, Hospital Universitari Germans Trias i Pujol, Badalona, Barcelona

5 CIBER, Madrid, Spain

Corresponding author

\section{Hugo Uchima, MD}

Endoscopy Unit, Gastroenterology Department, Hospital Universitari Germans Trias i Pujol, Carretera de Canyet S/N, Badalona, Barcelona 08916, Spain huchima.germanstrias@gencat.cat

\section{References}

[1] Werner YB, Hakanson B, Martinek J et al. Endoscopic or surgical myotomy in patients with idiopathic achalasia. N Engl J Med 2019; 381: 2219-2229 
[2] Grimes KL, Bechara R, Shimamura Y et al. Gastric myotomy length affects severity but not rate of post-procedure reflux: 3-year follow-up of a prospective randomized controlled trial of double-scope per-oral endoscopic myotomy (POEM) for esophageal achalasia. Surg Endosc 2020; 34: 29632968

[3] Teitelbaum EN, Sternbach JM, El Khoury R et al. The effect of incremental distal gastric myotomy lengths on EG] distensibility during POEM for achalasia. Surg Endosc 2016; 30: 745-750

[4] Baldaque-Silva F, Marques M, Vilas-Boas F et al. New transillumination auxiliary technique for peroral endoscopic myotomy. Gastrointest Endosc 2014; 79: 544-545
[5] Tanaka S, Kawara F, Toyonaga T et al. Two penetrating vessels as a novel indicator of the appropriate distal end of per-oral endoscopic myotomy. Dig Endosc 2017; 30: 206211

Bibliography

Endoscopy 2022; 54: E85-E87

DOI 10.1055/a-1388-6444

ISSN 0013-726X

published online 15.3.2021

(C) 2021. Thieme. All rights reserved.

Georg Thieme Verlag KG, Rüdigerstraße 14,

70469 Stuttgart, Germany

\section{ENDOSCOPY E-VIDEOS}

https://eref.thieme.de/e-videos

口居 Endoscopy E-Videos is an open access online section, 回触: reporting on interesting cases and new techniques in gastroenterological endoscopy. All papers include a high quality video and all contributions are freely accessible online. Processing charges apply (currently EUR 375), discounts and wavers acc. to HINARI are available.

This section has its own submission website at

https://mc.manuscriptcentral.com/e-videos 